\title{
Emotional Facial Expression Based on Action Units and Facial Muscle
}

\author{
Ahmad Hoirul Basori, Hani Moaiteq Abdullah AlJahdali \\ Faculty of Computing and Information Technology Rabigh, King Abdulaziz University, Jeddah, \\ Kingdom of Saudi Arabia
}

\begin{tabular}{|c|c|}
\hline Article Info & ABSTRACT \\
\hline Article history: & The virtual human play vital roles in virtual reality and game. The process of \\
\hline Received Jun 20, 2016 & $\begin{array}{l}\text { Enriching the virtual human through their expression is one of the aspect that } \\
\text { most researcher studied and improved. This study aims to demonstrate the }\end{array}$ \\
\hline Revised Aug 18, 2016 & combination of facial action units (FACS) and facial muscle to produce a \\
\hline Accepted Sep 28, 2016 & $\begin{array}{l}\text { realistic facial expression. The result of experiment succeed on producing } \\
\text { particular expression such as anger, happy, sad which are able to convey the }\end{array}$ \\
\hline Keyword: & $\begin{array}{l}\text { emotional state of the virtual human. This achievement is believed to bring } \\
\text { full mental immersion towards virtual human and audience. The future works }\end{array}$ \\
\hline $\begin{array}{l}\text { Emotional expression } \\
\text { Facial animation }\end{array}$ & $\begin{array}{l}\text { will able to generate a complex virtual human expression that combines } \\
\text { physical factos such as wrinkle, fluid dynamics for tears or sweating. }\end{array}$ \\
\hline
\end{tabular}

Facial muscle

Virtual human

Copyright (c) 2016 Institute of Advanced Engineering and Science. All rights reserved.

\section{Corresponding Author:}

Ahmad Hoirul Basori

Faculty of Computing and Information Technology Rabigh,

King Abdulaziz University,

Jeddah, Kingdom of Saudi Arabia

Email: uchiha.hoirul@gmail.com

\section{INTRODUCTION}

Game and virtual reality application built with some core components such as: building, the character (human or animal), environment, grass, trees etc. All these elements are affect the realism of virtual reality game itself. Some researcher studied the human character to be realistic as the real world by enriching with facial expression, voice/speech, and haptic technology [1]-[3]. While there is researcher that focus on conversational dialogue to give character more live and attractive. It can help human interact or make some dialogue then got response from the character through their AI behavior [3].

Fabri et.al. (1999) explain that virtual reality that has collaborative features facilitae its user to do communication using their facil expression, eye gaze, body and hand gesture. There two main obstacle on producing the realistic virtual human: first, how to build emotion database, then second obstacle is how to apply the emotion that stored in database to the character (human or animal) in order to achieve their goal. The other researcher argued that human character not only determined by the physical appearance, it also need some believability perspective [4],[5]. Therefore, some author produced an individual character that has behavior, emotion aspect and even gender. It has been continued by other researcher by considering the environment elements: shadow, light composition and filter to express the emotion content [6]. Zagalo and Torres (2008), has demonstrate a character that express their emotion by demonstrating the touching effects among two characters, this touching refer to an expression like hug, handshaking etc. Although touching activities occurred on virtual environment, it can affect the emotional condition of user, therefore it can be use as medium to strengthen the emotional expression of virtual characters. This study proposed a different approach on facial animation using muscle based and action units, where the muscle element is used to strengthen the emotional sensation of human characters. 


\section{RELATED WORKS}

The research of virtual human has reveal numerous method to express emotion thrugh the avatar. Table 1 present state of the art of diverse method to convey the emotional expression.

Table 1. Overview of virtual human study

\begin{tabular}{|c|c|}
\hline Avatar or virtual world features & Author \\
\hline $\begin{array}{l}\text { An avatar that imitate human behavior according to its } \\
\text { role and emotional context. It also provide avatar with } \\
\text { rich individuality that can make autorespon to its } \\
\text { surrounding }\end{array}$ & {$[5],[7],[8]$} \\
\hline $\begin{array}{l}\text { Am avatar with rich emotional features: body contact } \\
\text { such as hugging and handshake }\end{array}$ & [2] \\
\hline $\begin{array}{l}\text { The emotional expression of virtual human through facial } \\
\text { expression that supported by lighting, filter and shadow }\end{array}$ & [6] \\
\hline $\begin{array}{l}\text { Virtual human with visual and sound effect to convey the } \\
\text { emotion }\end{array}$ & [9]-[10] \\
\hline $\begin{array}{l}\text { The other author offer a rich interaction with visual and } \\
\text { haptic features }\end{array}$ & [11]-[12] \\
\hline $\begin{array}{l}\text { Produce haptic pajama that has visual and haptic features } \\
\text { to enrich the interaction }\end{array}$ & [13] \\
\hline $\begin{array}{l}\text { Combine visual, acoustic and haptic to improve realism } \\
\text { of virtual human expression }\end{array}$ & {$[14],[15]$} \\
\hline $\begin{array}{l}\text { Genrae extreme expression by combining Tears and } \\
\text { sweat with emotional facial expression }\end{array}$ & {$[16],[17]$} \\
\hline $\begin{array}{l}\text { Calculate the oxygenation absorption of facial human } \\
\text { tissue to render realistic facial skin }\end{array}$ & [18] \\
\hline $\begin{array}{l}\text { Integrate the human pose walking with facial expression } \\
\text { to enrich the avatar emotional expression }\end{array}$ & [19] \\
\hline
\end{tabular}

\subsection{Pseudomuscle-based Technique for Facial Animation}

Facial animation techniques consist of some different approaches such as key framing based on shape interpolation, performance-driven animation, parameterized models, pseudomuscle-based, musclebased and linguistic focused simulation [20]. Based on the popularity interpolation, it seems that key framing technique attracts the animator to produce conventional animation. While in parameterized model, the model is created from a group of parameters. It also involves geometric transformation, region interpolation and mapping approach to generate face planar. Pseudomuscle-based technique has a muscle element which is controlled by mathematical operator calculation for deformation purposes. Muscle-based technique is built from mass and spring to produce certain muscle animations (see Figure 1 for the illustration of muscle based rendering).
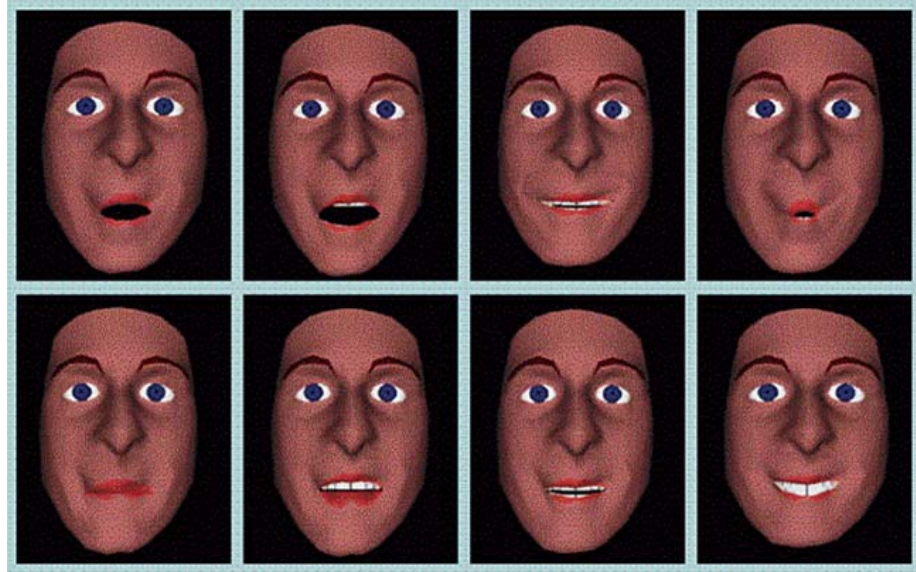

Figure.1 Muscle based rendering example picture taken from http://doi.ieeecs.org/cms/Computer.org/dl/mags/cg/2001/01/figures/g10187.gif

The well-known researcher who creates muscle-based facial expression is Parke in 1972 and 1974 [21]-[22] which has been extended by Keith Waters [23]. Waters enhances muscle facial expressions by 
using parameterized method. Waters' work is based on FACS theory which uses action unit for the muscle movement (see Figure 2).

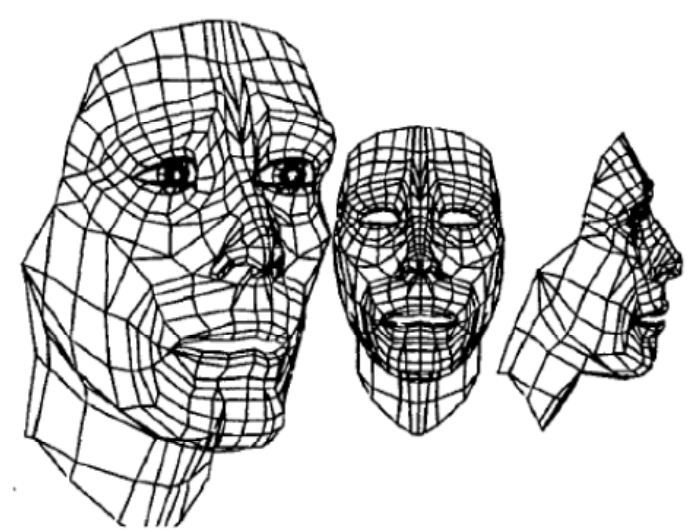

Figure 2. Action unit AU1 on parameterized-muscle model [23]

The combination of the Action Units is intended to create six fundamental emotions such as: neutral, happy, disgust, fear surprise and anger. The six emotions that Waters proposed are well illustrated in Figure 3. All of the facial models are created by changing the muscle model using parameter for each fundamental emotion.

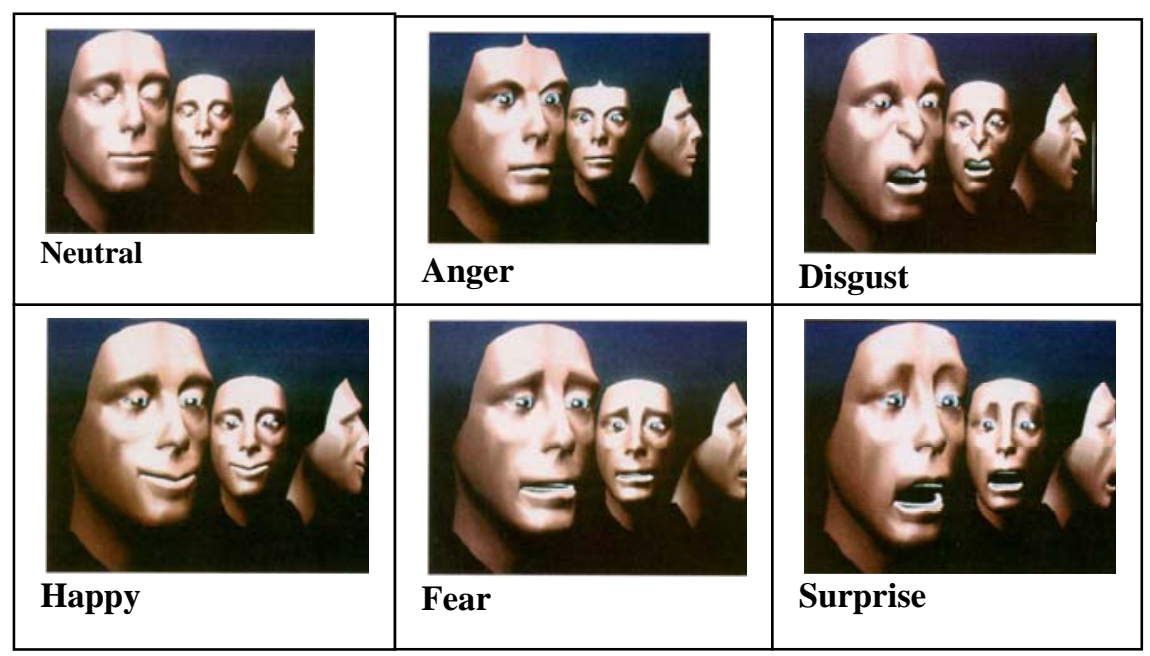

Figure 3. Parameterized-muscle models on expressing six basic emotions [23]

\subsection{Interpolation Technique for Facial Animation}

The method of shape interpolation on facial animation is broadly used by facial animators to construct polygonal surface on $3 \mathrm{D}$ face. Interpolation concept in a one-dimension area can be computed through two value and interpolation coefficient $\alpha$, refer to equation.

Value $=\alpha\left(\right.$ value $\left._{1}\right)+(1.0-\alpha) \quad\left(\right.$ value $\left._{2}\right) \quad 0.0<\alpha<1.0$

This value will be used as a control point to change the facial expression into another face expression. Interpolation techniques can be categorized into several ways as shown in Table 2 . 
Table 2. Interpolation techniques [24]

\begin{tabular}{|c|c|}
\hline Interpolation & Details \\
\hline $\begin{array}{l}\text { Key Expression } \\
\text { Interpolation }\end{array}$ & $\begin{array}{l}\text { The transformation of face is utilizing control point which is moved in } \\
\text { a straight frame [21]. If surface model is static, modification of model } \\
\text { is only possible in vertex level. }\end{array}$ \\
\hline $\begin{array}{l}\text { Bilinear Expression } \\
\text { Interpolation }\end{array}$ & $\begin{array}{l}\text { Bilinear concept has several ways to express polygonal surface on } 3 \mathrm{D} \\
\text { face. Bilinear blend of four key poses can be obtained from four } \\
\text { expressions generated using two interpolation parameters. }\end{array}$ \\
\hline $\begin{array}{l}\text { N-Dimensional } \\
\text { Expression Interpolation }\end{array}$ & $\begin{array}{l}\text { Technique for } \mathrm{N} \text {-Dimensional uses four interpolation factors and } \\
\text { sixteen key expressions to generate four-dimension interpolation } \\
\text { room. }\end{array}$ \\
\hline $\begin{array}{l}\text { Pairwise Expression } \\
\text { Interpolation }\end{array}$ & $\begin{array}{l}\text { Advanced technique for expression interpolation uses numerous } \\
\text { expression poses which are selected and built by interpolation factor } \\
\text { to merge with chosen poses. The control value for this method is } \\
\text { starting pose, end pose and interpolation value. }\end{array}$ \\
\hline $\begin{array}{l}\text { Facial Region } \\
\text { Interpolation }\end{array}$ & $\begin{array}{l}\text { This technique is to split face area into some independent regions. For } \\
\text { example, Kleiser splits face area into two regions i.e. upper and lower } \\
\text { region which enable users to manipulate emotion and speech at the } \\
\text { same time [25]. }\end{array}$ \\
\hline
\end{tabular}

The most popular muscle based and action units facial animation tchniques is shape nterpolation that allowed user to combine the multiple shape to perform particular shape. Shape Interpolation allows user to combine numerous pre-sculpted expressions to produce desired facial expression. The avatar 3D model consists of a lot of vertices that build the mesh. Vertices carry a lot of information such as position of vertices $(\mathrm{x}, \mathrm{y}, \mathrm{z})$ and index. Generally, there are two different sub-types of vertex animation called Morph animation and pose animation.

\subsection{Morph Animation}

Morph animation is the basic and simple animation that manipulates key frame time line with mesh snapshot interpolation. The technique is considered as old technique which is used prior to skeletal animation [26]. Morph animation is a variety of approach that involves entire series of vertex data to be interpolated e.g. animation for running. This method is quite fast when animation involves the whole mesh due to the easy modification among the keyframes. Nevertheless, this approach is not suitable for this facial animation because it cannot support multiple morph animation.

\subsection{Pose Animation}

Pose animation is the latest technique widely used for complex animation such as facial animation or skeletal animation. This technique concern on blending multiple discrete poses, expressing, articulating as an offset to foundation vertex by considering different weight to produce the final result. In this case, this study uses pose animation for the avatar facial expression. Pose animation is a blend shape interpolation technique commonly used in facial animation because each facial expression is placed in different animations. To produce facial expression completely, pose animation technique utilize a collection of orientation pose that pre-defined inside mesh which is called as an off set towards original vertex data.

\section{RESEARCH METHOD}

Development of interpolation is initiated after neutral appearance which named as facial expression base. Numerous of singular targets for particular appearance are produced by reassigning vertices from the original mesh. This technique needs parallelism of mesh structure among goal and origin mesh (identical amount of numerous vertex and triangle). Goal is measured by Degree of Freedom (DOF) $\phi_{i}$ which has cost 0 and 1. The DOF responsible on interpolation process. Merged vertices location is a spot that has DOF $>0 . \mathrm{DOF}=0$ corresponding to OFF or No EFFECT. The equation to calculate merged vertices location and weighted combination is exposed in equation 2 and 3.

$$
\begin{aligned}
& v^{\prime}=v_{\text {base }}+\sum \phi_{i} \bullet\left(\Delta v_{i}\right) \\
& \text { Where } \Delta v_{i}=v_{i}-v_{\text {base }} \\
& X^{\prime}=\sum_{i=0} w_{i} X_{i}
\end{aligned}
$$


The mixed location is attained from the original location plus goal spot with DOF $>0$. The entire posture simulation shown as a diagram as shown in Figure 4. Emotion as an input controls merger stance progression and stances assortment.

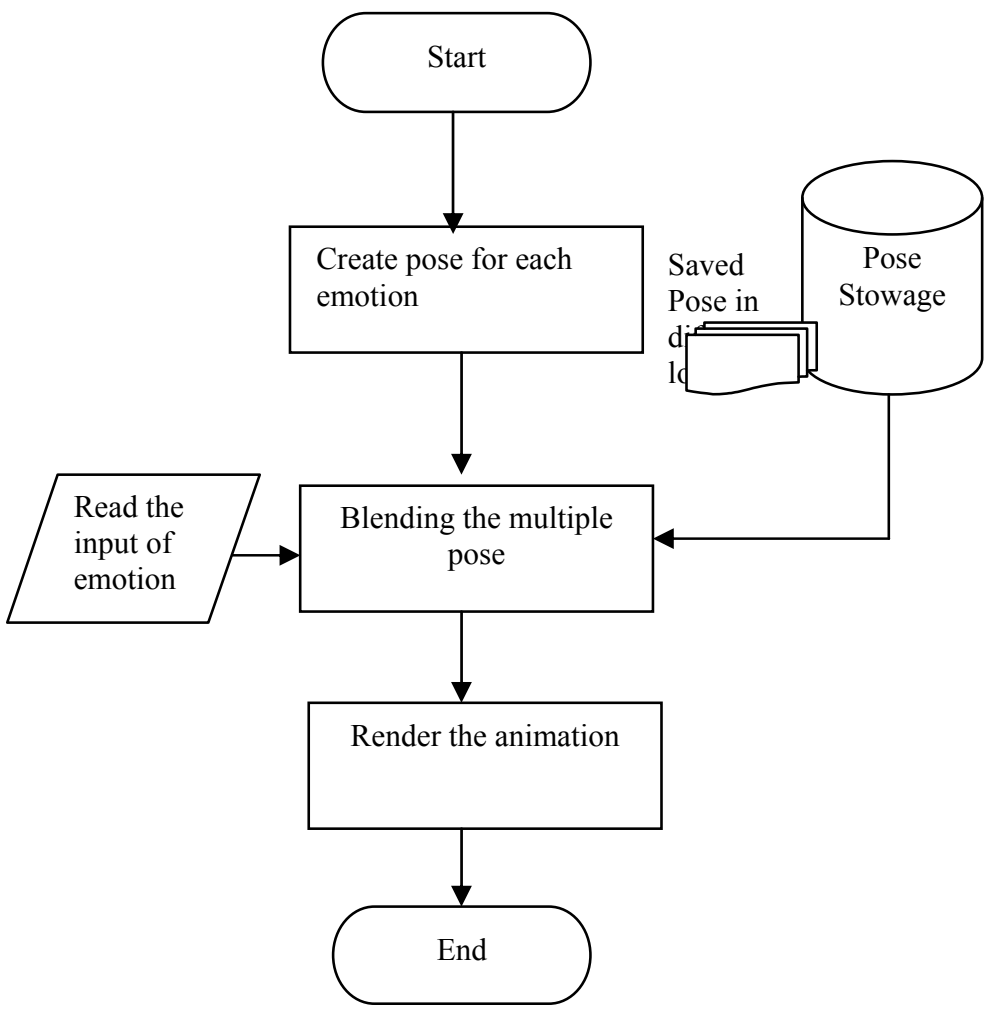

Figure 4. Flowchart Pose Animation

The procedure of filling the facemask mesh is exposed in C\# code fragment (refer to Figure 5).

\begin{tabular}{|l|}
\hline Algorithm loading 3D model \\
\hline Input facialmesh \\
1: Create animation for 'manual' mode \\
2: Set Vertex animation track \\
3: Generate Keyframe using vertex track \\
Output Loaded 3D facial object \\
\hline
\end{tabular}

Figure 5. C\# fragment code for loading the 3D model

As shown in equation 2 and 3, blend shape interpolation is suitable for muscle and Action Units approach. Facial Action Coding System has become a standard to control facial expression of human since it has revealed complete classification of human facial region [16]. This approach gives advantages to computer graphics animator to perform emotional facial expression on virtual human. The initial FACS is created from human facial pictures by distributing the face into specific sections. Each section donates on creating precise appearance, refer to Figure 6. 


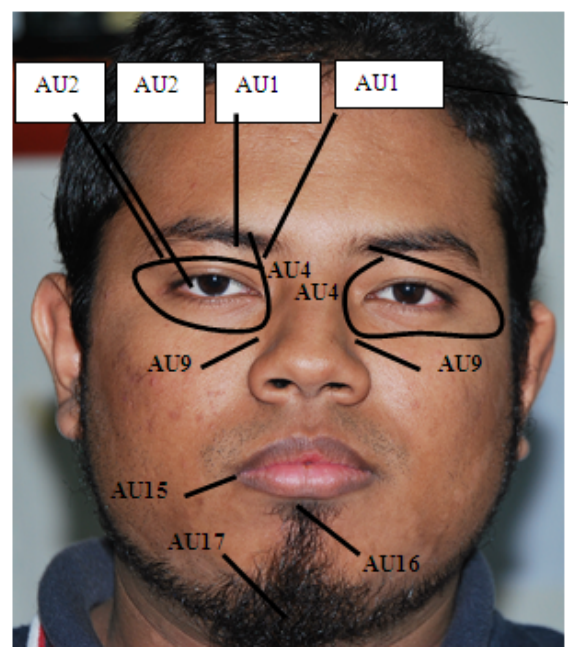

Figure 6. Facial Action Coding Systems (FACS) and its Action Units-1

Figure 6 and 7 show spot of Action Units (AUs); the detailed meaning of every Action units is structurized as follow: AU1(Inner Brow Raise), AU2(Outer Brow Raise), AU4(Brow Lower), AU9(Nose Wrinkler), AU15(Lip Corner Depressor),AU17(Chin Raiser).

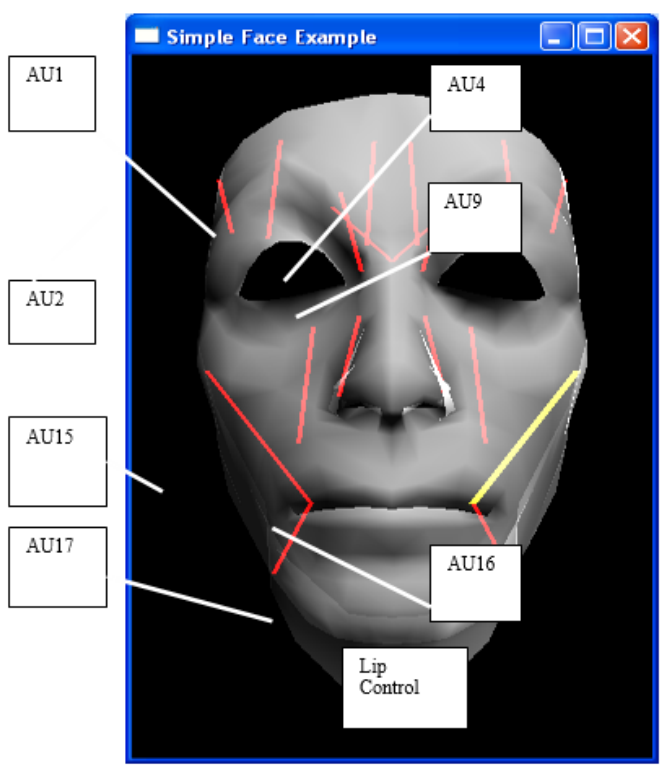

Figure 7. Facial Action Coding Systems (FACS) and its Action Units-2

Note:

Red and green line is portraying the muscle shape and position for the face model.

\section{RESULT AND DISCUSSION}

The emotion expression of avatar is generated using combination of Action Units on facial muscle. Each action units will contribute each other to perform realistic facial expression. Blend shape interpolation technique is utilized base shape as a reference for other emotion expression. Figure 8-13 are the result of facial rendering for several emotion expressions using a combination of action units and facial muscle. 


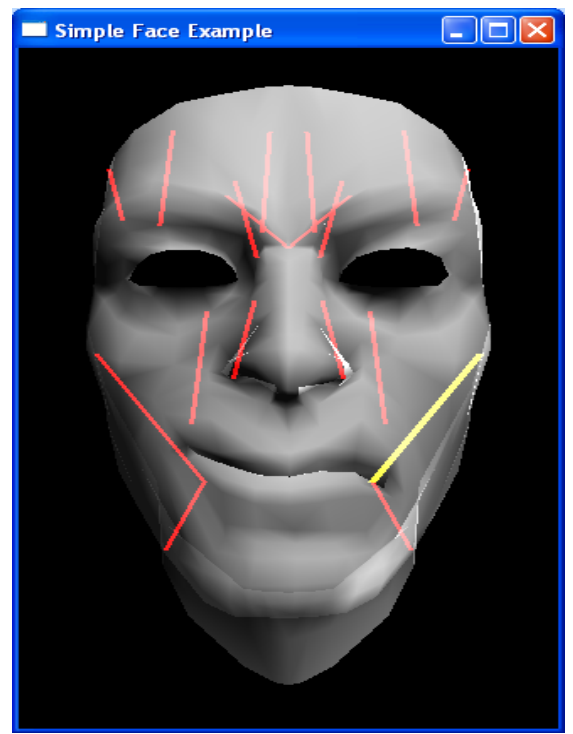

Figure 8. Disgust expression

Figure 8 show that muscle near mouth is contracted to produce disgust expression. AU1 and AU2 responsible to control eyebrow strength, if combine with AU4, can perform happiness look. Lip control/muscle and AU15 handle lip progression although emotion is produced. All fragments are working organised to produce happy look in the character. The intensity of the happiness can be controlled by level power (refer to Figure 9A and 9B).

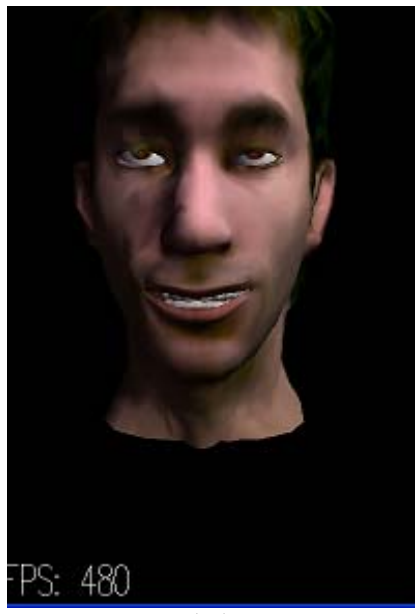

(A)

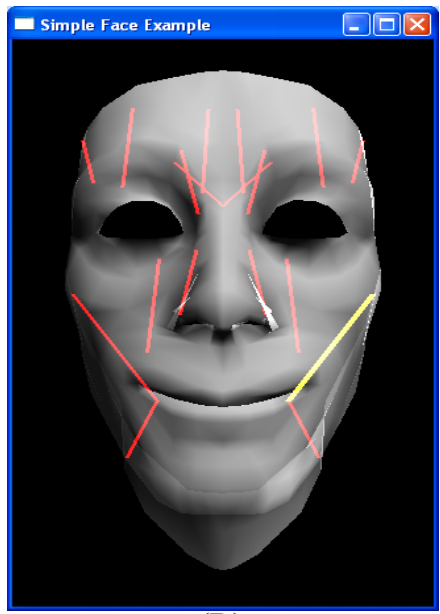

(B)

Figure 9. Happy Expression

Happy is an expression that have more focus on manage the lip synchronization that is why facial muscle near lip is very important to produce certain expression.

On the other hand, anger is an opposite felling of happy that also depend on lip control as well. AU1 and AU2 corresponded to produce a look nearby the eyebrow, while AU4 generate crinkle and increase the area near forehead. AU9 fortifies anger look by building crinkles nearby nose. AU15\&AU17 arrange lip angle and chin appearance (refer to Figure 10A and 10B). 


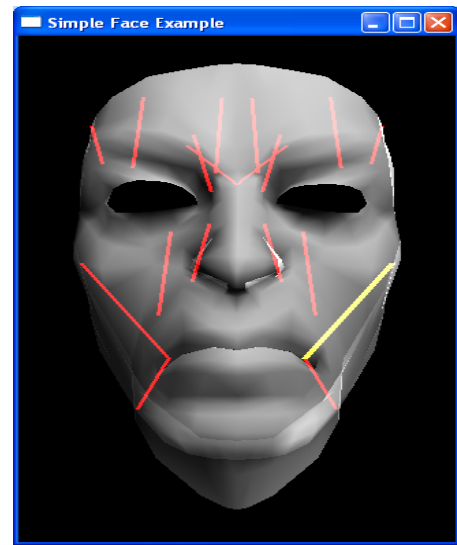

(A)

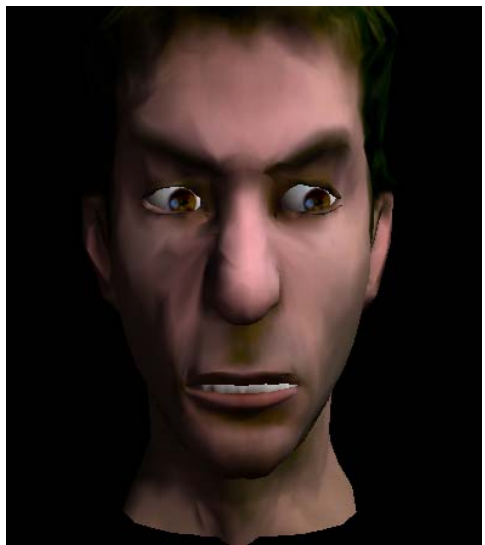

(B)

Figure 10. Anger expression

Sadness expression is an expression that pull down AU2 that make eyes looks like tired and the AU15 is pull down as well as shown in Figure 14 and 15.
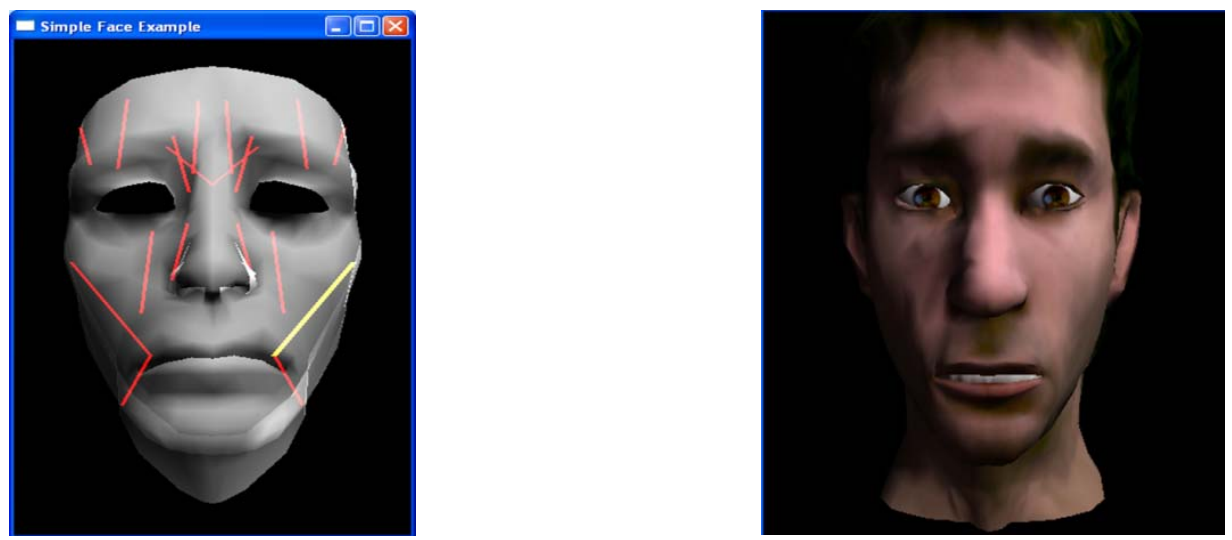

Figure 11. Sadness expression

Whilst, fear expresion is kind of expression between happy and anger that focus on eyes and lip manipulation. the eyes are wide open hoever the AU2 still pull down and mouth is little bit opened as shown in Figure 12.

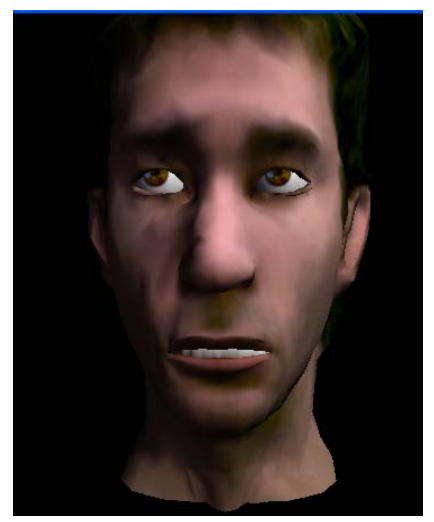

Figure 12. Fear expression 


\section{CONCLUSION}

Facial animation is very challenging research in computer graphics area. Action Units and Facial muscle approach is very attractive and adaptable to be used in movie or training application. In this paper we have shown the capability of action units and facial muscle to perform particular emotion expression. The implementation result portray that rendering artificial face is looks realistic. The future research will focus on developing facial muscle method with detail parameter that can perform wrinkle on face area.

\section{ACKNOWLEDGEMENTS}

Authors are grateful to Faculty of Computing and Information Technology Rabigh, King Abdulaziz University, Kingdom of Saudi Arabia

\section{REFERENCES}

[1] A. Garc, et al., "Emotional face expression profiles supported by virtual human ontology: Research Articles," Comput. Animat. Virtual Worlds, vol/issue: 17(3-4), pp. 259-269, 2006.

[2] N. Zagalo and A. Torres, "Character emotion experience in virtual environments," Vis. Comput.Springer-Verlag, vol/issue: 24(11), pp. 981-986, 2008.

[3] D. Traum, "Talking to Virtual Humans: Dialogue Models and Methodologies for Embodied Conversational Agents," Modeling Communication with Robots and Virtual Humans, Springer Berlin, Heidelberg, 2008.

[4] M. Fabri, et al., "The Emotional Avatar: Non-verbal Communication Between Inhabitants of Collaborative Virtual Environments," in Proceedings of the International Gesture Workshop on Gesture-Based Communication in Human-Computer Interaction, Springer-Verlag, 1999.

[5] A. G. Rojas, et al., "Individualized reaction movements for virtual humans," in Proceedings of the 4th international conference on Computer graphics and interactive techniques in Australasia and Southeast Asia, ACM: Kuala Lumpur, Malaysia, 2006.

[6] C. Melo and A. Paiva, "Expression of Emotions in Virtual Humans Using Lights, Shadows, Composition and Filters," in Proceedings of the 2nd international conference on Affective Computing and Intelligent Interaction, Springer-Verlag: Lisbon, Portugal, 2007.

[7] Z. Wang, et al., "Construction of Virtual Assistant Based on Basic Emotions Theory," Springer Berlin, Heidelberg, 2005 .

[8] A. G. Rojas, et al., "Simulation of individual spontaneous reactive behavior," in Proceedings of the 7th international joint conference on Autonomous agents and multiagent systems, International Foundation for Autonomous Agents and Multiagent Systems: Estoril, Portugal, vol. 1, 2008.

[9] K. Balc1, et al., "Xface Open Source Project and SMIL-Agent Scripting Language for Creating and Animating Embodied Conversational Agents," in MM’07, September 23-28, 2007, ACM: Augsburg, Bavaria, Germany, 2007.

[10] N. Bee, et al., "Simplified facial animation control utilizing novel input devices: a comparative study," in Proceedings of the 13th international conference on Intelligent user interfaces, ACM: Sanibel Island, Florida, USA, 2009.

[11] C. Sandor, et al., "Exploring Visuo-Haptic Mixed Reality," 2007 [cited 2010].

[12] K. Sato, et al., "Haptic telexistence," in ACM SIGGRAPH 2007 emerging technologies, ACM: San Diego, California, 2007.

[13] J. Teh and A. D. Cheok, "Internet and Internet Pajama: Novel Systems for Remote Haptic Interaction," in The 5th Workshop on Network \& System Support for Games 2006 - NETGAMES 2006, ACM: Singapore, pp. 1-2, 2006.

[14] A. H. Basori, et al., "The feasibility of human haptic emotion as a feature to enhance interactivity and immersiveness on virtual reality game," in Proceedings of The 7th ACM SIGGRAPH International Conference on Virtual-Reality Continuum and Its Applications in Industry, ACM, Singapore, pp. 1-2, 2008.

[15] A. H. Basori, et al., "An Integration Framework For Haptic Feedback To Improve Facial Expression On Virtual Human," International Journal of Innovative Computing, Information and Control, 2012.

[16] A. H. Basori and Qasim A. Z., "Extreme expression of sweating in 3D virtual human," Computers in Human Behavior. Vol. 35, pp. 307-314, 2014. Available from, DOI: 10.1016/j.chb.2014.03.013.

[17] Alkawaz M. H., et al., "Realistic facial expression of virtual human based on color, sweat, and tears effects," Sci World J, vol. 9, 2014.

[18] Alkawaz M. H., et al., "Oxygenation absorption and light scattering driven facial animation of natural virtual human," Multimedia Tools and Applications, pp. 1-37. DOI: 10.1007/s11042-016-3564-2.

[19] A. H. Basori, "Emotion walking for humanoid avatars using brain signals," International Journal of Advanced Robotic Systems, InTech, pp. 1-11, 2013. doi: 10.5772/54764.

[20] F. I. Parke, "Techniques for Facial Animation,New Trends in Animation and Visualization," edited by N. M. Thallman and D. Thalmann, New York, John Wiley and Sons, pp. 229-241, 1991.

[21] F. I. Parke, "Computer Generated Animation of Faces," University of Utah, Master Thesis, Salt Lake City, 1972.

[22] F. I. Parke, "A Parametric model for Human Faces," University of Utah, PhD Thesis, Salt Lake City, 1974.

[23] K. Waters, "A Muscle Model for Animating Three-Dimensional Facial Expression," ACM, Computer Graphics, vol/issue: 21(4), 1987.

[24] F. Parke and K. Waters, “Computer Facial Animation,” Massachusetts, AK Peters, Ltd Wellesley, 2008. 
[25] J. A. Kleiser, "Fast, Efficient, Accurate Way to Represent the Human Face," in State of the Art in Facial Animation, SIGGRAPH '89 Tutorials, New York, ACM, 1989.

[26] P. Ekman and W. V. Friesen, "Facial Action Coding System: A Technique for The Measurement of Facial Movement," Palo Alto, California, Consulting Psychologists Press, Inc., 1978.

\section{BIOGRAPHIES OF AUTHORS}

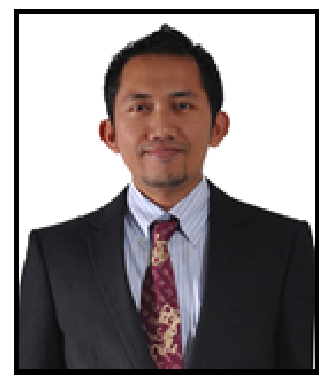

Ahmad Hoirul Basori, was born in Wirowongso Village, jember City, Indonesia, in 1982. He received the B.Sc (Software Engineering) from Institut Teknologi Sepuluh Nopember Surabaya in 2004 and the Ph.D (Computer Graphics) from Universiti Teknologi Malaysia, Johor Bahru, Johor, in 2011. From 2004 to present, he was a lecturer with the Department of Informatics, Faculty of Information Teknologi, Institut Teknologi Sepuluh Nopember Surabaya, Indonesia. In 2011, he has appointed as Assistant Professor with the Department of Computer Graphics and Multimedia, Universiti Teknologi Malaysia. Currently, he is appointed as Associate Professor of Faculty of Computing and Information Technology Rabigh, King Abdulaziz University. He is the member of Editorial board of some international journal, more than 32 articles, and also a member of professional membership IEEE, ACM SIGGRAPH, IAENG and Senior Member of IACSIT. His research interests include Computer Graphics, Facial Animation, Cloth Simulation, Medical Visualization, Haptic Interaction, Man Machine Interaction and Robotics.

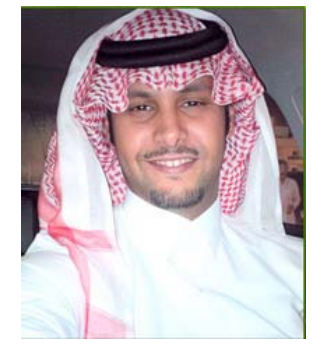

Hani Moaiteq Abdullah AlJahdali was born in Jeddah, Saudi Arabia, in 1983. He received the BSc (Computer Science), in 2005 from King AbdulAziz University in Jeddah. In 2009, He received the MSc in (Information Technology) and the $\mathrm{PhD}$ (Computer Science) from the University of Glasgow in 2015. From 2005 to 2007, he was working at the Saudi Electricity Company as a Budget and System analyst. In 2011, he has appointed as a lecturer with the department of Information Systems, King AbdulAziz University. Currently, he is appointed as an Assistant Professor of Faculty of Computing and Information Technology in Rabigh, King AbdulAziz University. His research interests include Information Security, Human Computer Interaction, Graphical Password Authentication and Robotics. 